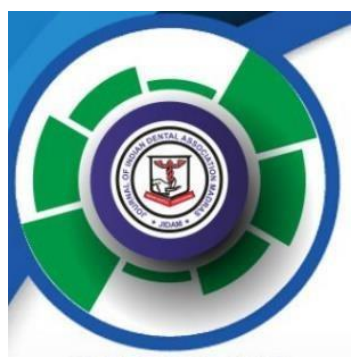

SYTSTEMATIC REVIEW

\title{
A SYSTEMATIC REVIEW TO EVALUATE THE POST- OPERATIVE COMPLICATIONS FOLLOWING FREE FIBULA FLAP FOR MANDIBULAR RECONSTRUCTION IN AN ADULT POPULATION
}

\author{
Dr. Manasi Bavaskar, Dr. Aashish Deshmukh, Dr. Thomson Mariadasan Dcruz \\ Department of Oral and Maxillofacial Surgery, Y.M.T. Dental College, and Hospital, Institutional Area, Sector 4, \\ Kharghar, Navi Mumbai - 410210, Maharashtra, India
}

DOI: 10.37841/jidam_2021_V8_I2_02

Address for Correspondence

Dr. Manasi Bavaskar,

Postgraduate Student,

302, Abhiyanta CHS, Plot Number 4,

Sector 42, Nerul (W), Navi Mumbai - 400706,

Maharashtra, India

Email id: drmanasi05@gmail.com

Received: 04.05.2021 First Published: 03.06.2021

Accepted: 28.05.2021

Published: 27.06.2021

\section{ABSTRACT}

The objective is to evaluate the basic complications such as necrosis, infection, fistula, dehiscence, and hematoma at recipient site and the donor site; as well as the incidence in failure of the Free Fibula Flap when used in mandibular reconstruction. After thorough electronic search on different databases, applying the inclusion and exclusion criteria, following the PRISMA guidelines and assessing the risk of bias; 6 articles were deemed eligible for this analysis. The total number of recipient site complications was the highest, i.e., $30.49 \%$ followed by the donor site complications with 9.75\% and flap loss with $9.34 \%$. The authors emphasize that success of the Free Fibula Flap depends not only on the major post-operative complications but also on the avoidance of the basic complications that occur at the recipient site as well as the donor site.

KEYWORDS: Free Fibula Flap, Mandibular Reconstruction, Complications. 
Manasi et al: Post-op Complications after free fibula flap for mandibular reconstructions in Adults

\section{INTRODUCTION:}

Mandible plays a pivotal role in mastication, articulation, deglutition, and respiration; as well as defines the contour of the lower third of the face ${ }^{1}$. Interruption in the continuity of mandible, therefore, produces both a cosmetic as well as a functional deformity ${ }^{1}$. It results in deviation, malocclusion, temporomandibular joint pain, soft tissue contracture and scar formation ${ }^{1}$. Hence, reconstruction of mandibular defects after trauma or tumor resection is one of the most challenging problems faced by the reconstructive surgeons.

The free fibula flap (FFF) was introduced to reconstructive surgical practice for traumatic tibial defects by Taylor et $\mathrm{al}^{2}$ in 1975 . Later in 1989 , Hidalgo ${ }^{3}$ reported the successful use of the flap in 12 patients with postresective segmental mandibular defects. Wei \& Seah et $\mathrm{al}^{4}$ saw $96.3 \%$ success rate of FFF in composite mandibular defects. The adaptability of the flap is further extended by the incorporation of osteotomy of the fibula. Jones et $\mathrm{al}^{5}$ performed a single transverse osteotomy, forming two struts, which created the versatile 'double barrel' fibula. Bahr et $\mathrm{al}^{6}$ subsequently adapted and popularized this technique. More recently, oromandibular reconstruction with osteocutaneous fibula free flap and endosseous implants became the treatment of choice for patients who underwent enbloc resection. Zlotolow et $\mathrm{al}^{7}$ successfully demonstrated functional prosthetic rehabilitation in microvascular fibula free flap reconstructed mandibles by placing osseointegrated implants.

Literature reveals an increased risk of post-operative complications while using the FFF. Several studies have tried to elucidate risk factors such as age, tobacco use, comorbidities and operating time for early and late postoperative complications ${ }^{8}$. Early complications encountered are flap necrosis, infections, fistulas, dehiscence or hematoma formation ${ }^{9}$. Late post-operative complications warrant interventions that involve removal of the fixation plating due to loosening of screws, plate fracture, plate exposure, and infection if sufficient soft tissue is not available for watertight primary closure ${ }^{10}$.

On the basis of the data available on the use and complications of FFF's in head and neck reconstructions, most studies are found to be descriptive and also lack statistical analysis ${ }^{8}$. Therefore, the purpose of this systematic review was to analyze the incidence of flap failure, and also the basic post-operative complications such as necrosis, infection, fistula, dehiscence and hematoma at the recipient and donor site when employing free fibula flap for mandibular reconstruction.

\section{MATERIALS AND METHODS:}

A comprehensive systematic review search in accordance with the PRISMA guidelines was made of relevant publications in databases from 1995 to 2019. Search engines used were PubMed and Google Scholar. An initial search was conducted with a combination of keywords; 'Free Fibula Flap', 'Mandibular reconstruction', 'outcomes', and 'complications'. These results were combined with the Boolean operators 'AND', 'OR', 'NOT'. 'Free fibula flap for mandibular reconstruction' AND 'outcomes' AND 'complications' NOT 'virtual planning' NOT 'prostheses were used eventually. All abstracts were reviewed, and articles written in English language and described as prospective clinical trials, retrospective cohorts, case series, and randomized controlled trials were selected for the study (Figure 1).

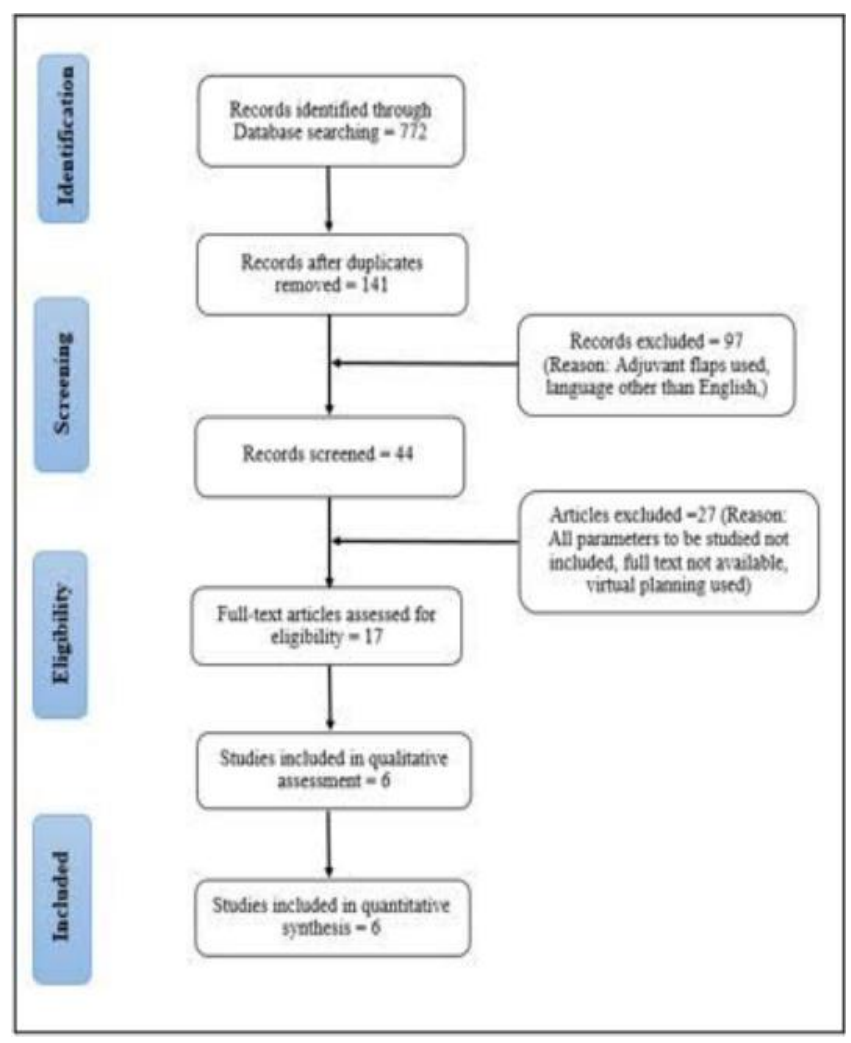

Fig 1: Study Flow Diagram

The focus question for this review was 'What is the incidence of post-operative complications associated with Free Fibula Flap when used for mandibular reconstruction?' in which the PICOS criteria was considered. Included studies comprised of those with adult population having mandibular defect caused by trauma, tumor, malignancy, osteoradionecrosis or osteomyelitis, with only Free Fibula Flap used for reconstruction. Only retrospective or prospective cohort studies, randomized controlled trials, case series and reports were considered appropriate. Also,

Volume No: 8, Issue No: 2 
Manasi et al: Post-op Complications after free fibula flap for mandibular reconstructions in Adults

the articles which reported the incidence of flap failure, recipient site (RS) and donor site (DS) complications were included. Studies involving adjunctive use of any other flap for reconstruction, treatment done with virtual surgical planning, animal studies, literature reviews, studies with only abstract and studies not written in English were excluded from the review.

The review aimed in evaluating the basic postoperative complications using the following parameters: a) incidence of failure of the free fibula flap used in mandibular reconstruction, b) recipient site complications (necrosis, infection, fistula, dehiscence and hematoma), and c) donor site complications (necrosis, infection, fistula, dehiscence and hematoma). Two reviewers independently scanned each title and abstract of the studies to narrow down and subsequently read the full articles of those that were potentially eligible. Only those studies that met the predefined inclusion criteria were considered eligible for the systematic review (Table 1). A detailed study design of each included study was then tabulated (Table 2).

TABLE 1: ARTICLES REVIEWED.

\begin{tabular}{|c|c|c|c|c|}
\hline $\begin{array}{l}\text { Article } \\
\text { No. }\end{array}$ & Title & Year & Type of Study & $\begin{array}{c}\text { Duration of } \\
\text { Study }\end{array}$ \\
\hline 1 & $\begin{array}{l}\text { Yamamoto N, Morikawa T, Yakushiji T, Shibahara T. } \\
\text { Mandibular reconstruction with free vascularized fibular graft. } \\
\text { The Bulletin of Tokyo Dental College. 2018:2017-0025. } .^{[1]}\end{array}$ & 2018 & Clinical report & $\begin{array}{rr}\text { Jan 03 - } & \text { Jan } \\
17 & \end{array}$ \\
\hline 2 & $\begin{array}{l}\text { Camuzard O, Dassonville O, Ettaiche M, Chamorey E, } \\
\text { Poissonnet G, Berguiga R, Leysalle A, Benezery K, Peyrade F, } \\
\text { Saada E, Hechema R. Primary radical ablative surgery and fibula } \\
\text { free-flap reconstruction for T4 oral cavity squamous cell } \\
\text { carcinoma with mandibular invasion: oncologic and functional } \\
\text { results and their predictive factors. European Archives of Oto- } \\
\text { Rhino-Laryngology. } 2017 \text { Jan 1;274(1):441-9. }{ }^{[12]}\end{array}$ & 2016 & Retrospective & $\begin{array}{c}\text { Jan 2001- July } \\
2013\end{array}$ \\
\hline 3 & $\begin{array}{l}\text { Lodders JN, Schulten EA, De Visscher JG, Forouzanfar T, } \\
\text { Karagozoglu KH. Complications and risk after mandibular } \\
\text { reconstruction with fibular free flaps in patients with oral } \\
\text { squamous cell carcinoma: a retrospective cohort study. Journal of } \\
\text { reconstructive microsurgery. } 2016 \text { Jul;32(06):455-63. }{ }^{[8]}\end{array}$ & 2015 & Retrospective & $\begin{array}{c}\text { April } 95 \text { to Sep } \\
13\end{array}$ \\
\hline 4 & $\begin{array}{l}\text { Hoffman GR, Islam S, Eisenberg RL. Microvascular } \\
\text { reconstruction of the mouth, face and jaws. Oromandibular } \\
\text { reconstruction-free fibula flap. Australian dental journal. } 2012 \\
\text { Sep;57(3):379-87. } .^{[13]}\end{array}$ & 2012 & Retrospective & $\begin{array}{c}\text { Sep } 05 \text { to June } \\
11\end{array}$ \\
\hline 5 & $\begin{array}{l}\text { González-García R, Naval-Gías L, Rodríguez-Campo FJ, } \\
\text { Muñoz-Guerra MF, Sastre-Pérez J. Vascularized free fibular flap } \\
\text { for the reconstruction of mandibular defects: clinical experience } \\
\text { in } 42 \text { cases. Oral Surgery, Oral Medicine, Oral Pathology, Oral } \\
\text { Radiology, and Endodontology. } 2008 \text { Aug 1;106(2):191-202. }{ }^{[9]}\end{array}$ & 2008 & Prospective & 1996 to 2001 \\
\hline 6 & $\begin{array}{l}\text { Peled M, El-Naaj IA, Lipin Y, Ardekian L. The use of free } \\
\text { fibular flap for functional mandibular reconstruction. Journal of } \\
\text { oral and maxillofacial surgery. } 2005 \text { Feb } 1 ; 63(2): 220-4 .^{[14]}\end{array}$ & 2005 & Retrospective & $1997-2002$ \\
\hline
\end{tabular}


Manasi et al: Post-op Complications after free fibula flap for mandibular reconstructions in Adults

TABLE 2: DETAILS OF DESIGN OF INCLUDED STUDIES.

\begin{tabular}{|c|c|c|c|c|c|c|c|c|c|c|c|c|c|}
\hline \multirow{2}{*}{$\begin{array}{l}\text { Article } \\
\text { No. }\end{array}$} & \multirow[t]{2}{*}{ Author } & \multirow{2}{*}{$\begin{array}{c}\text { Total number of } \\
\text { Patients who } \\
\text { underwent FFF }\end{array}$} & \multirow{2}{*}{$\begin{array}{c}\text { Flap } \\
\text { Failure }\end{array}$} & \multicolumn{5}{|c|}{$\begin{array}{c}\text { Recipient Site (RS) } \\
\text { Complications }\end{array}$} & \multicolumn{5}{|c|}{$\begin{array}{c}\text { Donor Site (DS) } \\
\text { Complications }\end{array}$} \\
\hline & & & & $\mathrm{N}$ & $\bar{I}$ & $\bar{F}$ & $\mathrm{D}$ & $\mathrm{H}$ & $\overline{\mathrm{N}}$ & $\bar{I}$ & $\bar{F}$ & $\bar{D}$ & $\overline{\mathrm{H}}$ \\
\hline 1 & $\begin{array}{c}\text { Nobuharu } \\
\text { Yamamoto }^{[11]}\end{array}$ & 08 & 0 & 2 & - & - & - & - & - & - & - & - & - \\
\hline 2 & $\begin{array}{c}\text { Olivier Camuzard } \\
{[12]}\end{array}$ & 77 & 7 & $\overline{-}$ & 12 & 11 & - & 8 & 8 & $\overline{-}$ & - & $\overline{-}$ & 2 \\
\hline 3 & J. N. Lodders ${ }^{[8]}$ & 85 & 9 & 10 & - & 9 & 9 & - & 1 & 1 & - & $\overline{1}$ & - \\
\hline 4 & GR Hoffman ${ }^{[13]}$ & 21 & 1 & 2 & 1 & 1 & - & - & - & - & - & 1 & - \\
\hline 5 & González $^{[9]}$ & 42 & 4 & - & 2 & 2 & 5 & 1 & - & 1 & 1 & 3 & 1 \\
\hline 6 & Micha Peled ${ }^{[14]}$ & 13 & 2 & - & - & - & - & - & - & 4 & - & - & - \\
\hline & & $\mathrm{N}=246$ & $\mathrm{~N}=23$ & 14 & 15 & 23 & 14 & 9 & 9 & 5 & 1 & 5 & 3 \\
\hline
\end{tabular}

Abbreviations: N (Necrosis), I (Infection), F (Fistula), D (Dehiscence), H (Hematoma), N (Total)

Two review authors independently assessed the risk of bias of each included study using the Cochrane Handbook for Systematic Reviews of Interventions. The graphical representation of the same is depicted in Figure B.

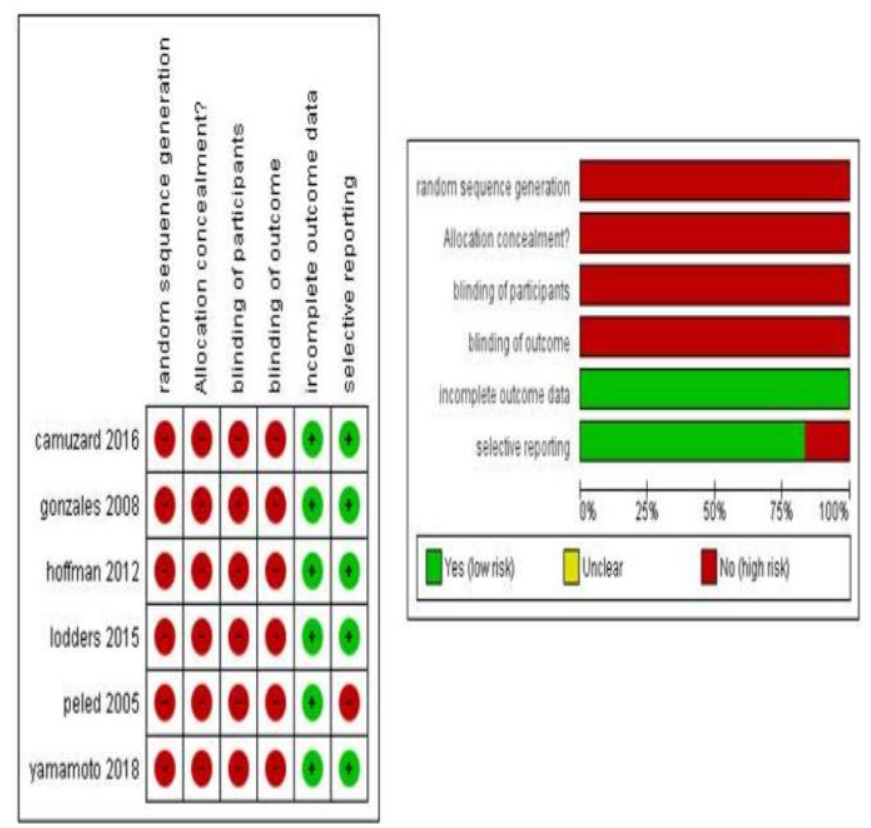

Fig 2: Risk of Bias Summary

\section{RESULTS:}

According to the data achieved from the 6 suitable articles, Graph 1 gives the comprehensive distribution of complications in a total of 246 patients. The Graph 2 indicates that a total of $49.97 \%$ showed no complications in the RS nor the DS; offering a success rate close to $50 \%$ for FFF in mandibular reconstruction.

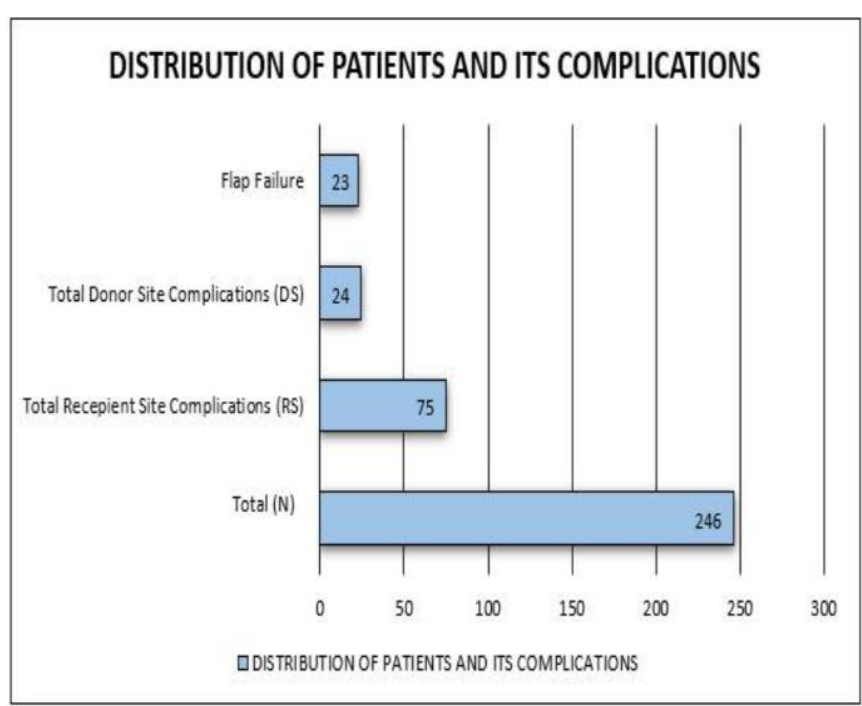

Graph 1: The Distribution of Patients and its Complications

Volume No: 8, Issue No: 2 
Manasi et al: Post-op Complications after free fibula flap for mandibular reconstructions in Adults

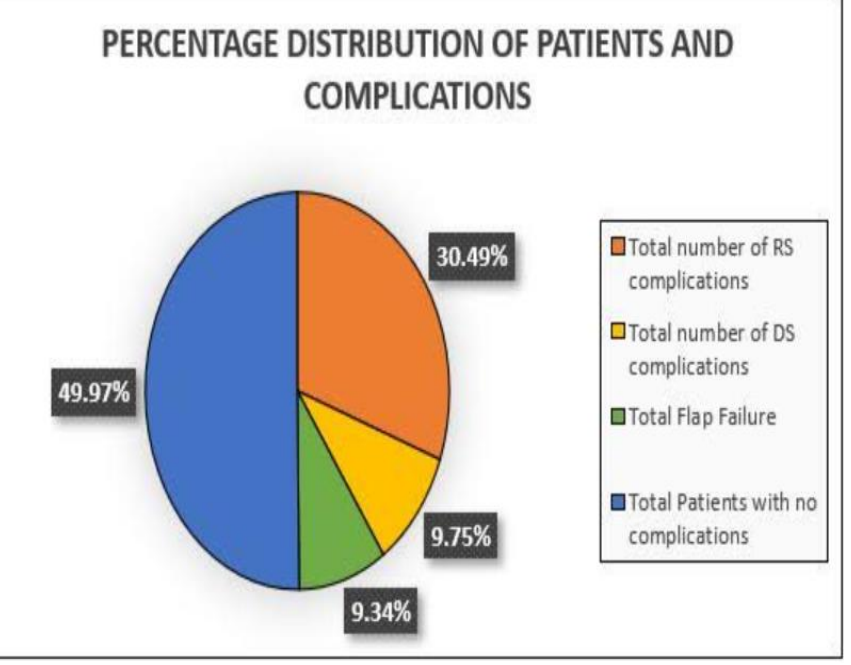

Graph 2: Percentage Distribution of Patients and its Complications

It was also observed that the highest complication rate was seen at the recipient site i.e., in 75 of 246 patients, which accounted to $30.49 \%$ of the total distribution. The donor site complications and the rate of flap failure were nearly the same i.e., $9.75 \%$ and $9.34 \%$ respectively.

A specific evaluation of complications for both RS and DS was also studied (Graph 3). Wherein, the RS complication revealed that, fistula had the highest rate of presentation which accounted to $30.6 \%$. This was followed by infection with a rate of $20 \%$, necrosis and dehiscence had the same prevalence of about $18.6 \%$ each and hematoma was the least seen complication, with a rate of $4 \%$ only.

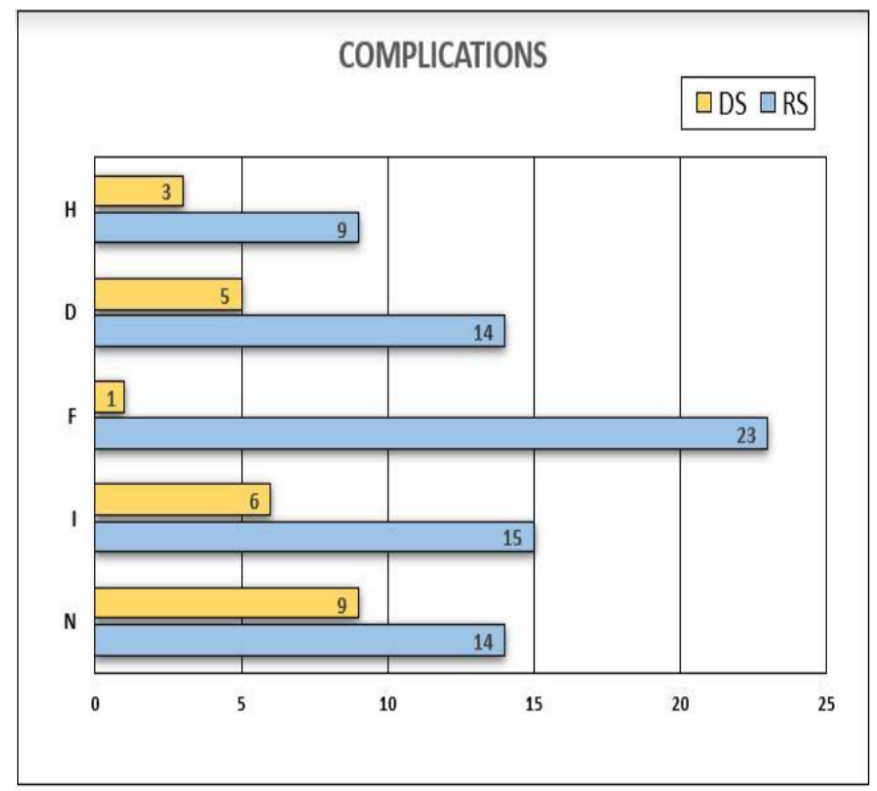

Graph 3: Comparison of Complication Rate at Recipient Site and Donor Site

In the DS complications, necrosis presented with an exceptionally high rate of $37.5 \%$, followed by infection and dehiscence with a rate of $25 \%$ and $20.8 \%$ respectively, hematoma in $12.5 \%$ and fistula with a rate of $4.1 \%$ only. A stark difference was noted in fistula formation between the RS and DS.

\section{DISCUSSION:}

Among the many causes, malignancy of the oral cavity, osteoradionecrosis after radiotherapy, congenital deformities, trauma and ballistic injuries are few of the leading reasons for mandible deformation ${ }^{15}$. Historically, the results of oromandibular reconstruction were unfortunately disastrous, notably at a time when surgery was restricted to direct closure, or at best, locoregional flap repair ${ }^{13}$. The patient's appearance following such surgeries was epitomized by the 'Andy Gump' cartoon figure of the $1930 \mathrm{~s}^{13}$. Over the previous 15 years, reconstruction of large mandibular defects has essentially been transformed by the use of osseous microsurgical free flaps, such as the fibula, iliac crest, and scapula ${ }^{16}$. The advent of these numerous bone grafts with its versatility have now become the preferred treatment modality for mandibular reconstruction. However, each of these options have their own merits and demerits.

The vascularized fibula flap is considered as the first choice for reconstruction of mandibular continuity defects in oral cavity cancer patients ${ }^{8}$. The success rates of FFF vary between $92.9 \%$ and $100 \% .^{8.9}$ Fibula bone has a thicker cortex than the scapula, radius, or ilium and therefore, resembles more closely to the mandible than any other graft $^{17}$. The possibility of several osteotomies because of the periosteal blood supply allows for its better contour and adaptation $^{9,18}$. The added benefit of its ability to be combined with other skin flaps for reconstruction of composite defects, suitability for osseointegrated dental implant and display of a 2-team approach makes it a reliable flap in maxillofacial reconstruction ${ }^{9,18}$.

Even though, FFF presents with certain disadvantages; various modifications are available to overcome the same. One of the disadvantages being the inadequate height of bone obtained; was attenuated by the introduction of double barrel fibular graft ${ }^{9}$. The use of double-barrel FFF was first described by Bahr et al. ${ }^{6}$ in 1998, which allowed to obviate the disadvantage of limited graft height relative to the original mandible in dentate patients ${ }^{17}$. Another issue observed with FFF was the variability of cutaneous perforators and the limited size of skin island ${ }^{9}$. A controversy exists in the literature, regarding the viability of the skin paddle as an oral seal for which, it is recommended to make use of a larger paddle by incorporating a cuff of soleus to help ensure adequate blood supply by means of

Volume No: 8, Issue No: 2 
Manasi et al: Post-op Complications after free fibula flap for mandibular reconstructions in Adults

including as many septo-cutaneous vessels as possible to the skin flap ${ }^{17,9}$. Moreover, the distal third of the lower leg seems to be the most dependable region for obtaining the skin island, ensuring additional reliability ${ }^{9,17}$. Comprehending the above numerous assets and a handful liabilities of FFF, it is crucial to have a thorough surgical plan when incorporating it for mandibular reconstruction.

As with any microsurgical flap, the complications related to the use of FFF in reconstruction of continuity defects of the mandible have been extensively studied; and are reported to occur at the recipient site as well as the donor site. The incidence of post-operative complications following reconstruction using FFF published in the literature ranges from $22 \%$ to $33 \%{ }^{12,16,19}$ Whereas, in our search and systematic analysis, we observed a postoperative complication rate of $50.03 \%$; out of which, the highest contribution was from the complications that occurred at the RS, that accounted for $30.49 \%$. The complications at recipient site could be catastrophic and are predominantly associated with primary thrombotic occlusion at the anastomosis ${ }^{13}$. Novakovic et al ${ }^{20}$ stated that the majority of failures at RS are prone to occur within the first 48 hours and can be managed effectively with immediate revision surgery. The later surgical interventions are predominantly caused by infection, wound dehiscence, osteonecrosis and plate fracture ${ }^{10}$. The inference to be marked is that there is an increased predisposition of complications that could occur at the RS; fistula formation being the most frequent, as analysed in this study. Followed by infection as another cause, along with necrosis and dehiscence that could account for an increased rate of recipient site complication after FFF reconstruction.

In concordance with the included studies; appropriate pre-operative evaluation of the donor site was done prior to graft harvesting. The donor site presented relatively with fewer complications but, FFF may result in other morbidities such as compartment syndrome, distal ischemia, edema, ankle instability, restricted range of motion, foot drop, pain and impaired ambulation at the DS ${ }^{17,13}$. Anthony et $\mathrm{al}^{21}$ investigated a cohort study of 27 patients and identified that $17 \%$ of donor sites presented with immediate complications such as wound infection and skin graft loss. It also identified ankle stiffness (41\%), ankle instability $(10 \%)$, and transient pereneal motor weakness $(7 \%)$, as donor site morbidity ${ }^{13}$. There is enormous literature that focuses on the aforementioned morbidities at $\mathrm{DS}^{22-24}$; hence, our systematic review only emphasized on the additional complications such as necrosis, infection, fistula formation, dehiscence, and hematoma; out of which we concluded that necrosis had the highest rate of occurrence.

Furthermore, the rate of flap failure achieved from our analysis was $9.34 \%$, which is closely consistent with the data reported in previous literature. Lodders et $\mathrm{al}^{8}$ and $\mathrm{Wu}$ et $\mathrm{al}^{25}$ stated that FFFs have an increased risk for flap failure. Gonzales et $\mathrm{al}^{9}$ revealed that out of 38 patients, two patients presented with partial loss of the flap, one patient with total loss of the flap and at the end of the five-year follow-up period, five cases $(11.9 \%)$ showed partial/total loss of the flap although only two cases $(4.76 \%)$ developed loss of the bone.

Therefore, it is prudent to understand that the fibular graft with its numerous advantages does present with postoperative complications. This study highlighted the noticeably higher rate of basic complications at the recipient site as well as a considerable rate at the donor site; making it essential for the surgeons to be aware of them as well as stringently learn their management.

\section{DRAWBACKS:}

We appreciate that this review is a retrospective pooling of case series, which has led to the heterogenicity in the data collection. Recommendations for future research include the investigation of predictive patient and clinical risk factors as well as incorporation of the functional outcomes and quality of life of patients that contribute in the overall success of this flap in mandibular reconstruction.

\section{CONCLUSION:}

The pre-operative evaluation, intra-operative procedure and the post-operative assessment, all the three play a vital role in determining the success of a surgical procedure. Our systematic review highlighted the possibility and occurrence of basic post-operative complications that occur after the reconstructive surgery using Free Fibula Flap both at the recipient as well as the donor site. With an acceptable low morbidity rate at the donor site and considerable, but easily manageable complications at the recipient site; this review makes us aware about the importance of basic complications that are equally essential towards the success of Free Fibula Flap.

\section{CONFLICT OF INTEREST:}

There are no conflicts of interest related to this review.

\section{FUNDING AND SPONSORSHIP:}

This research did not receive any specific grant from funding agencies in the public, commercial, or not-forprofit sectors. 
Manasi et al: Post-op Complications after free fibula flap for mandibular reconstructions in Adults

\section{REFERENCES:}

1. Rao SG, Aditya TN, Gopinath KS, Anand K. Free fibula flap in the reconstruction of mandible: a report of six cases. J Maxillofac Oral Surg. 2009 Sep;8(3):275-8.

2. Taylor GI, Miller GD, Ham FJ. The free vascularized bone graft. A clinical extension of microvascular techniques. Plast Reconstr Surg. 1975 May;55(5):533-44.

3. Hidalgo DA. Fibula free flap: a new method of mandible reconstruction. Plast Reconstr Surg. 1989 Jul;84(1):71-9.

4. Wei FC, Seah CS, Tsai YC, Liu SJ, Tsai MS. Fibula osteoseptocutaneous flap for reconstruction of composite mandibular defects. Plast Reconstr Surg. 1994 Feb;93(2):294-304.

5. Jones NF, Swartz WM, Mears DC, Jupiter JB, Grossman A. The" double barrel" free vascularized fibular bone graft. Plast Reconstr Surg. 1988 Mar;81(3):378-85.

6. Bähr W, Stoll P, Wächter R. Use of the "double barrel" free vascularized fibula in mandibular reconstruction. J Oral Maxillofac Surg. 1998 Jan;56(1):38-44.

7. Zlotolow IM, Huryn JM, Piro JD, Lenchewski E, Hidalgo DA. Osseointegrated implants and functional prosthetic rehabilitation in microvascular fibula free flap reconstructed mandibles. Am J Surg. 1992 Dec;164(6):677-81.

8. Lodders JN, Schulten EA, De Visscher JG, Forouzanfar T, Karagozoglu KH. Complications and risk after mandibular reconstruction with fibular free flaps in patients with oral squamous cell carcinoma: a retrospective cohort study. J Reconstr Microsurg. 2016 Jul;32(6):455-63.

9. González-García R, Naval-Gías L, RodríguezCampo FJ, Muñoz-Guerra MF, Sastre-Pérez J. Vascularized free fibular flap for the reconstruction of mandibular defects: clinical experience in 42 cases. Oral Surg Oral Med Oral Pathol Oral Radiol Endod. 2008 Aug;106(2):191-202.

10. Van Gemert JT, Abbink JH, van Es RJ, Rosenberg AJ, Koole R, Van Cann EM. Early and late complications in the reconstructed mandible with free fibula flaps. J Surg Oncol. 2018 Mar;117(4):773-80.

11. Yamamoto N, Morikawa T, Yakushiji T, Shibahara T. Mandibular reconstruction with free vascularized fibular graft. Bull Tokyo Dent Coll. 2018 Nov 30;59(4):299-311.

12. Camuzard O, Dassonville O, Ettaiche M, Chamorey
E, Poissonnet G, Berguiga R, et al, Primary radical ablative surgery and fibula free-flap reconstruction for T4 oral cavity squamous cell carcinoma with mandibular invasion: oncologic and functional results and their predictive factors. Eur Arch Otorhinolaryngol. 2017 Jan;274(1):441-49.

13. Hoffman GR, Islam S, Eisenberg RL. Microvascular reconstruction of the mouth, face and jaws. Oromandibular reconstruction-free fibula flap. Aust Dent J. 2012 Sep;57(3):379-87.

14. Peled M, El-Naaj IA, Lipin Y, Ardekian L. The use of free fibular flap for functional mandibular reconstruction. J Oral Maxillofac Surg. 2005 Feb $1 ; 63(2): 220-24$.

15. Jarefors E, Hansson T. Functional outcome in 17 patients whose mandibles were reconstructed with free fibular flaps. J Plast Surg Hand Surg. 2017 Jun;51(3):178-81.

16. López-Arcas JM, Arias J, Del Castillo JL, Burgueño M, Navarro I, Morán MJ, et al, The fibula osteomyocutaneous flap for mandible reconstruction: a 15-year experience. J Oral Maxillofac Surg. 2010 Oct 1;68(10):2377-84.

17. Guerra MF, Gías LN, Campo FJ, González FJ. Vascularized free fibular flap for mandibular reconstruction: a report of 26 cases. J Oral Maxillofac Surg. 2001 Feb 1;59(2):140-44.

18. Shroff SS, Nair SC, Shah A, Kumar B. Versatility of fibula free flap in reconstruction of facial defects: a center study. J Maxillofac Oral Surg. 2017 Mar $1 ; 16(1): 101-7$.

19. Parise GK, Guebur MI, Ramos GH, Groth AK, da Silva AB, Sassi LM. Evaluation of complications and flap losses in mandibular reconstruction with microvascularized fibula flap. Oral Maxillofac Surg. 2018 Sep;22(3):281-84.

20. Novakovic D, Patel RS, Goldstein DP, Gullane PJ. Salvage of failed free flaps used in head and neck reconstruction. Head Neck Oncol. 2009 Aug $21 ; 1: 33$.

21. Anthony JP, Rawnsley JD, Benhaim P, Ritter EF, Sadowsky SH, Singer MI. Donor leg morbidity and function after fibula free flap mandible reconstruction. Plast Reconstr Surg. 1995 Jul;96(1):146-52.

22. Fang H, Liu F, Sun C, Pang P. Impact of wound closure on fibular donor-site morbidity: a metaanalysis. BMC Surg. 2019 Jul 5;19(1):81.

23. Ling XF, Peng $X$. What is the price to pay for a free fibula flap? A systematic review of donor-site morbidity following free fibula flap surgery. Plast Reconstr Surg. 2012 Mar 1;129(3):657-74.

24. Momoh AO, Yu P, Skoracki RJ, Liu S, Feng L, Hanasono MM. A prospective cohort study of 
Manasi et al: Post-op Complications after free fibula flap for mandibular reconstructions in Adults fibula free flap donor-site morbidity in 157 complications, outcomes and strategies for consecutive patients. Plast Reconstr Surg. 2011 Sep management of flap failure: analysis of 2019 flaps $1 ; 128(3): 714-20$.

25. Wu CC, Lin PY, Chew KY, Kuo YR. Free tissue in single institute. Microsurgery. 2014 Jul;34(5):339-44. transfers in head and neck reconstruction: 